This document is the accepted manuscript version of the following article:

Hundt, P. M., Tuzson, B., Aseev, O., Liu, C., Scheidegger, P., Looser, H., ...

Emmenegger, L. (2018). Multi-species trace gas sensing with dual-wavelength QCLS.

Applied Physics B: Lasers and Optics, 124(6), 108 (9 pp.).

https: //doi .org/10.1007/s00340-018-6977-y

\title{
Multi-species trace gas sensing with dual-wavelength QCLs
}

\author{
Morten Hundt ${ }^{1,}$, Béla Tuzson ${ }^{1}$, Oleg Aseev ${ }^{1}$, Chang Liu ${ }^{1}$, Philipp Scheidegger ${ }^{1}$, Herbert Looser ${ }^{1,3}$, Filip- \\ pos Kapsalidis², Mehran Shahmohammadi², Jérôme Faist ${ }^{2}$, and Lukas Emmenegger ${ }^{1}$ \\ ${ }^{1}$ Empa - Swiss Federal Laboratories for Materials Science and Technology, Laboratory for Air Pollution and Envi- \\ ronmental Technology, 8600 Dübendorf, Switzerland \\ 2ETH Zurich, Quantum Optoelectronics Group, 8093 Zürich, Switzerland \\ ${ }^{3} \mathrm{FHNW}$, Institute for Aerosol and Sensor Technology, 5210 Windisch, Switzerland \\ *Present address: MIRO Analytical Technologies $\mathrm{GmbH}, 8600$ Dübendorf, Switzerland
}

Corresponding author's email: Morten.Hundt@empa.ch

\begin{abstract}
Instrumentation for environmental monitoring of gaseous pollutants and greenhouse gases tends to be complex, expensive, and energy demanding, because every compound measured relies on a specific analytical technique. This work demonstrates an alternative approach based on mid-infrared laser absorption spectroscopy with dual-wavelength quantum cascade lasers (QCLs). The combination of two dual- and one single DFB-QCL yields high-precision measurements of $\mathrm{CO}(0.08 \mathrm{ppb}), \mathrm{CO}_{2}(210 \mathrm{ppb})$, $\mathrm{NH}_{3}(0.02 \mathrm{ppb}), \mathrm{NO}(0.4 \mathrm{ppb}), \mathrm{NO}_{2}(0.1 \mathrm{ppb}), \mathrm{N}_{2} \mathrm{O}(0.045 \mathrm{ppb})$, and $\mathrm{O}_{3}(0.11 \mathrm{ppb})$ simultaneously in a compact setup $\left(45 \times 45 \mathrm{~cm}^{2}\right)$. The lasers are driven time-multiplexed in intermittent continuous wave mode with a repetition rate of $1 \mathrm{kHz}$. The individual spectra are real-time averaged (1s) by a FPGA based data acquisition system. The instrument was shortly assessed for environmental monitoring and benchmarked with reference instrumentation to demonstrate its potential for compact multi-species trace gas sensing.
\end{abstract}

\section{Introduction}

Environmental trace gas monitoring is of high importance to assess human health risks in polluted urban or industrial environments, and also to efficiently mitigate climate change caused by greenhouse gas emissions. Gaseous pollutants that are to be measured by environmental monitoring stations according to current European regulations are $\mathrm{CO}, \mathrm{NO}_{x_{1}} \mathrm{SO}_{2}$, and $\mathrm{O}_{3}$ [1]. In addition, some stations monitor $\mathrm{NH}_{3}$ and the greenhouse gases $\mathrm{CO}_{2}, \mathrm{CH}_{4}$ and $\mathrm{N}_{2} \mathrm{O}$ [2]. Instruments that are used in environmental monitoring are based on a wide range of physical measurement principles that target specific compounds. Therefore, monitoring stations usually comprise many different instruments. Correspondingly, they require considerable logistic efforts, technical personnel, and relatively large infrastructure. Moreover, measurements of the important pollutant $\mathrm{NO}_{2}$ are based on chemiluminescence detection (CLD) of NO, which is an indirect method that relies on catalytic conversion of $\mathrm{NO}_{2}$, that is known to have cross sensitivities to other nitrogen containing compounds $[3,4]$.

A highly attractive alternative is offered by direct absorption laser spectroscopy in the mid-infrared spectral region. The wavelength range from 4 to $10 \mu \mathrm{m}$ has the inherent advantage of containing the funda- 
mental vibrational transition bands of most atmospheric molecules. Highly precise and selective measurements of individual species have already been demonstrated down to ppt (parts per trillion, 10-12) detection limits using quantum cascade lasers (QCLs) [5-7]. The simultaneous detection of all compounds of interest in environmental monitoring would, however, require a spectroscopic setup combining a large number of individual laser sources, given the limited tuning range of distributed feedback (DFB)-devices. A first attempt with four QCLs was realized in 2004 to measure four, spectrally separated, species in cigarette smoke [8]. Later studies reported the combination of up to three QCLs within one spectroscopic instrument [9-11]. The common drawback of these approaches is the increasing complexity of the optics and their sensitivity to mechanical instabilities with the addition of further laser sources. Similarly, the required hardware for controlling each laser temperature and current independently reaches rapidly the practical limits. Thus, the previously discussed combinations of three or more QCLs realized in a single setup led to large instruments with weight $>50 \mathrm{~kg}$, power consumption $>500 \mathrm{~W}$ and beyond 12 rack units in 19-inch frames.

These inherent limitations would be greatly reduced in case of broad-band laser sources with large spectral coverage. Although, such solutions exist (e.g. EC-QCLs, QCL frequency combs) they are still limited in spectral coverage, power, tuning speed, and stability to allow truly multicomponent, high precision trace gas measurements for long-term monitoring purposes. Recently, considerable efforts have been made to realize on-chip solutions to unify two complementary characteristics in mid-IR sources, namely broad tuning and high spectral resolution. These are realized with electrically tunable DFB devices or arrays of DFB devices. A detailed description of design, fabrication, and performance of the various solutions is given in recent reviews [12-14] and references therein.

In this paper, we adopt the solution of dual-wavelength devices $[15,16]$ in order to show their suitability for multi-species high-precision trace gas spectroscopy. Such devices - also called dual-section DFBs consist of two DFB sections, placed on a broad gain ridge, that emit single mode at two specific target frequencies. Corresponding QCLs were developed for detection of $\mathrm{NO}$ and $\mathrm{NO}_{2}$ in pulsed operation [17] and later for detection of $\mathrm{CO}, \mathrm{N}_{2} \mathrm{O}$, and $\mathrm{CO}_{2}$ in intermittent continuous (iCW) operation [18]. The latter revealed that the dual-section DFB QCL has an inherent etaloning effect, which can be partly suppressed, but requires some additional efforts such as applying anti-reflective coatings. Therefore, a further alternative was realized, also called neighbor DFB, where the two DFBs are placed about $25 \mu \mathrm{m}$ apart on the same gain material [19].

In the following, we show that several such dual-wavelength devices can be combined to realize a compact all-in-one environmental trace gas monitor. We present the optical layout, laser driving and data acquisition, discuss the system performance, and demonstrate its application to environmental monitoring.

\section{Experimental}

\section{a. Wavelength selection and dual-wavelength QC lasers}

Our measurement strategy for addressing a multitude of gaseous species is to identify spectral regions that contain ro-vibrational transitions of at least two compounds within a typical DFB-QCL tuning range 
$\left(\sim 1-2 \mathrm{~cm}^{-1}\right)$. Additionally, individual spectral windows should be located in a frequency range that can be covered by broad-gain QCL materials $\left(\sim 300 \mathrm{~cm}^{-1}\right)$. Figure 1 shows an overview of the simulated transitions of the target molecules using the HITRAN 2012 database [20]. Based on a systematic survey of these lines, we identified three particular regions where the above requirements are fulfilled. Table 1 summarizes the five target frequencies along with the corresponding species. These selections represent a good compromise between maximal line-strength, minimal interference from water vapor, and the objective to cover several target molecules within the scanning range of every laser.

Table 1: Overview of target frequencies, laser device types, and average output powers in iCW mode used for the multi-species gas sensor.

\begin{tabular}{|c|c|c|c|c|}
\hline Compound & $\begin{array}{c}\text { Wavenumbers } \\
\left(\mathrm{cm}^{-1}\right)\end{array}$ & Device type & Device number & $\begin{array}{c}\text { Average Power } \\
\text { (mW) }\end{array}$ \\
\hline $\mathrm{NH}_{3} ; \mathrm{O}_{3}$ & 1046.4 & Single DFB & $\mathrm{QCL}-3$ & 7 \\
\hline $\mathrm{NO}_{2}$ & 1597.3 & \multirow{2}{*}{ Neighbor DFB } & $\mathrm{QCL}-2$ (right) & 1 \\
\hline NO & 1900.0 & & QCL-2 (left) & 0.5 \\
\hline $\mathrm{CO} ; \mathrm{N}_{2} \mathrm{O} ; \mathrm{H}_{2} \mathrm{O}$ & 2190.2 & \multirow{2}{*}{$\begin{array}{c}\text { Dual-section } \\
\text { DFB }\end{array}$} & QCL-1 (front) & 2 \\
\hline $\mathrm{CO}_{2}\left({ }^{12} \mathrm{C} \&{ }^{13} \mathrm{C}\right)$ & 2282.9 & & QCL-1 (rear) & 1 \\
\hline
\end{tabular}

The frequencies listed in Table 1 were the targets for the QCL design and are described in more detail within a separate publication in this issue [19].

We chose to combine three different device types for our instrument, namely neighbor DFB, dual-section DFB, and a single-DFB QCL. This gives the possibility to evaluate and compare the optical properties and the analytical impact of the different approaches.

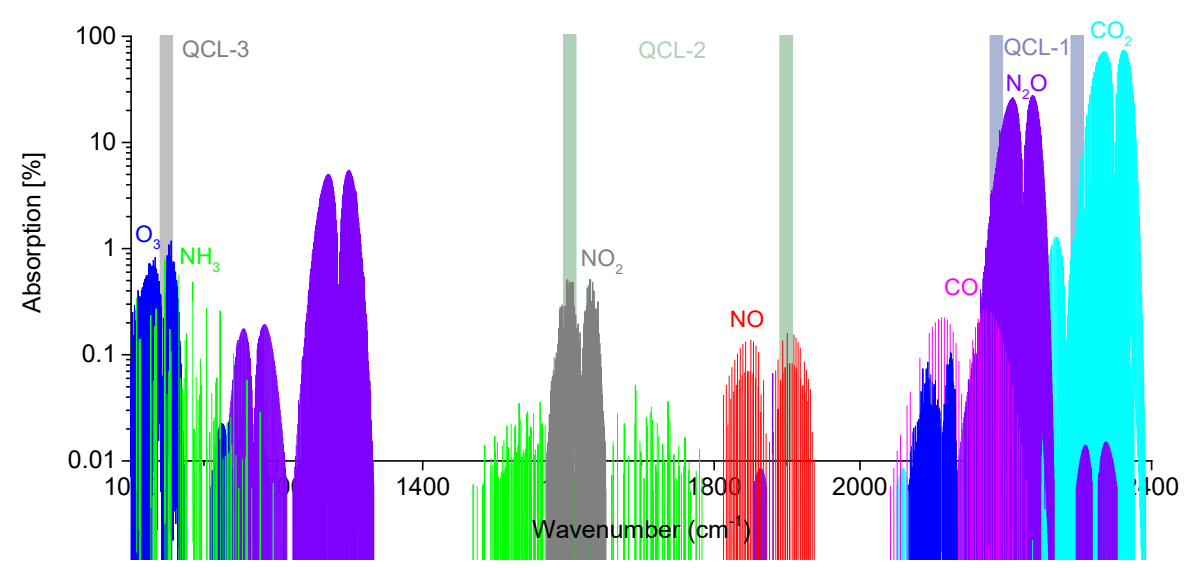

Figure 1: Simulated absorption of the target gases for typical ambient mole fractions $\left(\mathrm{O}_{3}: 100 \mathrm{ppb} \mathrm{NH}_{3}\right.$ : 5 ppb; $\mathrm{NO}_{2}: 100$ ppb; NO: 50 ppb; $\mathrm{CO}: 150$ ppb; $\mathrm{N}_{2} \mathrm{O}: 330$ ppb; $\mathrm{CO}_{2}: 400$ ppm), considering 76 m optical path length, $80 \mathrm{hPa}$, and $296 \mathrm{~K}$. The shaded areas mark the frequencies used in this study; the shading colors indicate the three different device types.

\section{b. Optical layout and beam combination}

A schematic of the optical layout for the multi-laser instrument is shown in Figure 2. The divergent outputs of the QCLs are focused with aspheric lenses $(f=6 \mathrm{~mm})$ such that their beam waist is matched 
to the multipass cell (AMAC-76, Aerodyne Research Inc. ). The beams are combined using a custom dichroic (Lohnstar Optics) optimized to reflect $4 \mu \mathrm{m}$ and transmit $\lambda>5 \mu \mathrm{m}$ and a wedged $\mathrm{CaF}_{2}$ beam splitter (BSW510, Thorlabs). While the dichroic is optimized for the reflection/transmission of the design wavelengths, the beam splitter causes loss of about $50 \%$ of the transmitted/reflected beams. The beam exiting the multipass cell is then focused onto a thermoelectrically cooled MCT detector (PVM-4TE-8, Vigo Systems, S.A.) using a spherical mirror with a focal length of $75 \mathrm{~mm}$.

A major challenge in optimizing the optical alignment in terms of optical fringe level is the two separate output beams of the neighbor DFB-QCL. Although, their spatial separation is as little as $25 \mu \mathrm{m}$ at the facet, the image at the center of the multipass cell shows a distance of $2.3 \mathrm{~mm}$ between the centers of the two beam spots due to the magnification of the optical system (see Figure 2). Therefore, the apparent width of the dual beam at the entrance to the multipass cell is about the same size as the coupling hole of the cell, which has a diameter of $4.2 \mathrm{~mm}$. Because of this proximity and the Gaussian character of the beams, scattering at the edge of the coupling hole can potentially cause severe interference fringes. Nevertheless, we found the multipass cell being tolerant enough to accept this mismatch in position and beam-waist and allowing for an efficient beam-folding and in/out-coupling of the beams. One key element to achieve good performance in terms of fringe level was to rotate the neighbor DFB-QCL by $90^{\circ}$, i.e., having the DFB-separation perpendicular to the optical plane defined by the multipass cell. This makes the aiming mismatch less critical with respect to the in-coupling angle. Furthermore, a piezoelectric vibrator mounted on the cell's rear mirror is used to randomize the optical fringes and thereby reduce their disturbing effect by spectral averaging [21].

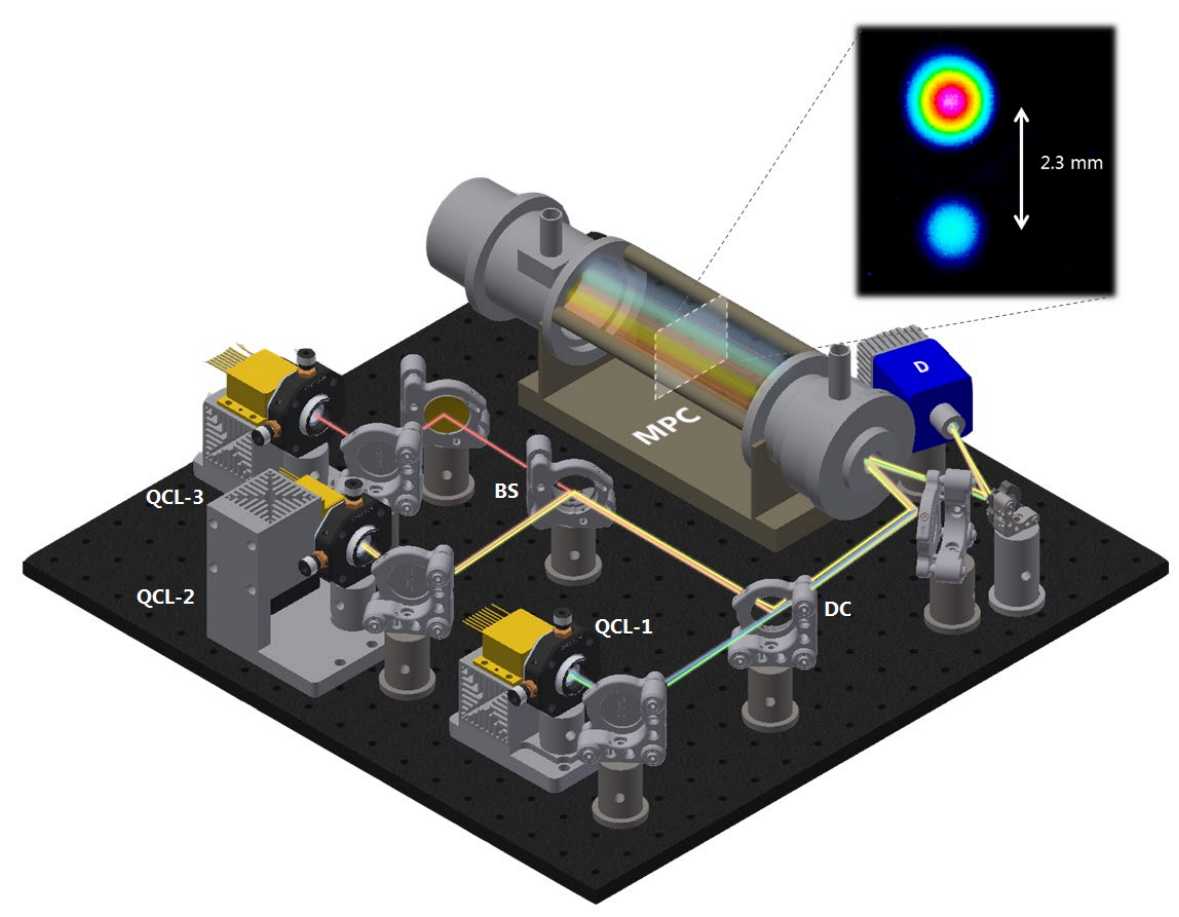

Figure 2: Model of the optical layout of the multi-laser instrument. The beams of three QCLs are combined using a dichroic (DC) and a $\mathrm{CaF}_{2}$ beam splitter (BS) before the merged beam is coupled into a $76 \mathrm{~m}$ long multipass absorption cell (MPC) and focused on the detector (D). The inset (top-right) shows an IR beam profile of the neighbor DFB QCL (QCL-2) recorded at $55 \mathrm{~cm}$ distance, corresponding to the center of the multipass cell. 
The optical alignment was optimized based on real-time inspection of the laser beam size and position by using an infrared beam profiler (WinCamD-IR-BB, DataRay Inc.). The insert in Figure 2 shows an example of the beam profile for the neighbor DFB-QCL measured at the center of the multipass cell corresponding to $55 \mathrm{~cm}$ distance from the source. The intensity difference is due to the difference in output power of the two DFBs.

\section{c. Laser driving and data acquisition}

The laser driving and data acquisition system used for this study is described in detail by Liu et al. [22] and thus, we only briefly review the functionalities of the system and its application for driving several multi-wavelength lasers and the associated data acquisition.

The impact of driving electronics noise on the spectral properties of QCLs has been investigated by several publications (see, e.g. Tombez et al. [23] and references therein). Estimating the laser linewidth (FWHM) as a function of the driver current noise spectral density, it was shown that a current noise of about $1 \mathrm{nA} / \mathrm{Hz}^{1 / 2}$ is needed before the intrinsic properties of QCLs are observed. Commercially available solutions fulfilling this requirement are still bulky devices with large heat dissipation. Obviously, combining many, in our case five, such drivers to drive multiple lasers would rapidly jeopardize the compactness of any setup. To overcome this limitation, we developed a more compact laser driver based on the concept of intermittent continuous wave (iCW) driving [24]. This approach leads to a compact, yet a flexible laser driver that eliminates the need for any external electronics (e.g. function generator or DAQ) for current modulation while maintaining a high modulation capability (up to $20 \mathrm{kHz}$ ), and considerably lowers the demands on power supply performance. Using the iCW driving it is possible to completely decouple the driver from the external power supply during laser operation. The laser current is solely provided by the charge stored in capacitors and also results in heat dissipation of less than $5 \mathrm{~W}$ for driving the five lasers. This especially facilitates the encapsulation of QCL devices into compact packages like HHL or even TO-3. The current noise level of this laser driver was demonstrated to be better than $1 \mathrm{nA} / \mathrm{Hz}^{1 / 2}$. Moreover, the current driver supports operating a wide range of multi-wavelength $\mathrm{QCL}$ device types and allows stacking for the purpose of multiple laser configurations. Its adaptation to the various driving situations is supported by numerous FPGA functionalities that were implemented on the System-on-Chip (SoC), such as flexible generation of a large variety of synchronized trigger signals and digital IOs. The same SoC is used to sample the spectroscopic signal at rates up to $125 \mathrm{MS} / \mathrm{s}$ with 14-bit resolution.

The system can support up to six lasers operated in a time multiplexed iCW driving scheme with a single detector [24]. The lasers are triggered in a predefined sequence with a total period of $1 \mathrm{~ms}$, while the pulse duration for each laser (-section) can be set individually with a time resolution of $8 \mathrm{~ns}$. For our setup, the dual-wavelength devices were operated with $25 \mu$ s pulse duration, while the single DFB device at $9.6 \mu \mathrm{m}$ was driven with $50 \mu$ s current pulses. During such a current pulse, the QCL heats up and therefore tunes rapidly in frequency. The lasers are completely turned off during the remaining time to lower the overall power consumption and hence to reduce the cooling requirements. This results in a duty cycle of $2.5 \%$ and $5 \%$ for the dual- and single-DFB-QCLs, respectively. The spectra of each QCL 
are recorded by the FPGA based data acquisition. Additionally, the detector zero level signal is measured for $5 \mu$ s at the beginning of each cycle and is used for spectral normalization.

The spectra are averaged in real-time by the FPGA and then transferred to a PC for spectral analysis by a custom written LabVIEW program. The FPGA system is also used to provide the full control of the spectrometer by reading out pressure and temperature values or setting laser temperatures and valve positions.

\section{d. Site and sampling for environmental monitoring}

Ambient air measurements of all parameters were performed in our laboratory at Empa (Dübendorf, Switzerland) for several days in early December 2017, linked to calibration standards and compared to standard air quality monitoring equipment. The location is suburban, densely populated and impacted by emissions from a close-by motorway.

We used a membrane pump (N920G, KNF) to constantly draw ambient air from outside through a PTFE tube of ten meter length and $4 \mathrm{~mm}$ inner diameter to the multipass cell of the laser spectrometer. The pressure in the cell was maintained at $75 \mathrm{hPa}$ by using a needle valve in the up-stream flow resulting in a gas flow of $1 \mathrm{l} / \mathrm{min}$ through the cell. A solenoid valve was used to switch periodically - once per hour for five minutes - between ambient air and calibrated reference gas. The calibration gas was free of NO, $\mathrm{NO}_{2}, \mathrm{NH}_{3}$, and $\mathrm{O}_{3}$ and was previously calibrated for mole fractions of $\mathrm{CO}(114.12 \pm 0.25 \mathrm{ppb}), \mathrm{CO}_{2}$ $(400.17 \pm 0.02 \mathrm{ppm})$ and $\mathrm{N}_{2} \mathrm{O}(322.77 \pm 0.09 \mathrm{ppb})$ using commercial cavity ringdown spectrometers (G1301 and G5310, Picarro Inc.). These periodic measurements of calibration/zero gas were used to correct for instrument drifts, which were mainly caused by ambient temperature variations. The measurements of $\mathrm{NO}$ and $\mathrm{NO}_{2}$ were compared to a commercial dual channel chemiluminescence detector (CLD) measuring $\mathrm{NO}$ and $\mathrm{NO}_{x}$ (APNA 360, Horiba), sharing the air inlet with the laser spectrometer. Other species $\left(\mathrm{CO}_{2}, \mathrm{CO}, \mathrm{O}_{3}\right)$ were compared to the measurements of the Dübendorf air quality monitoring site of the Swiss National Air Pollution Monitoring Network (NABEL) situated about $130 \mathrm{~m}$ from our sampling inlet. At the NABEL station, $\mathrm{CO}_{2}$ is monitored with a cavity ring-down spectrometer (G1301, Picarro Inc.), $\mathrm{CO}$ is measured by non-dispersive IR absorption (APMA 370, Horiba) and $\mathrm{O}_{3}$ by UV-absorption (49i, Thermo). Details about these measurements and their uncertainties can be found in the NABEL technical report [25]. $\mathrm{N}_{2} \mathrm{O}$ could not be compared directly to an alternative measurement technique; however, we verified our results by comparing to the reference gas bottle with $\mathrm{NH}_{3}$-free air and a known $\mathrm{N}_{2} \mathrm{O}$ mole fraction (322.77 $\pm 0.09 \mathrm{ppb}$ ). For $\mathrm{NH}_{3}$, stable reference gases are difficult to produce and no direct comparison was available.

\section{Results and Discussion}

\section{a. Instrument characterization}

The mole fractions were retrieved from the raw data by real-time least-square fitting of the transmission signals to a Voigt profile. The fitting model is based on spectral parameters taken from the HITRAN database [20] and experimental parameters such as optical path length, gas temperature, and 
pressure. The tuning rate of each $\mathrm{QCL}$ is obtained by inserting a 2-inch Germanium etalon with a free spectral range of $0.0244 \mathrm{~cm}^{-1}$ (at $5 \mu \mathrm{m}$ and $25^{\circ} \mathrm{C}$ ) in the laser beam path. Figure 3 shows the normalized and fitted spectra for the five wavelength regions that are used by the spectrometer.
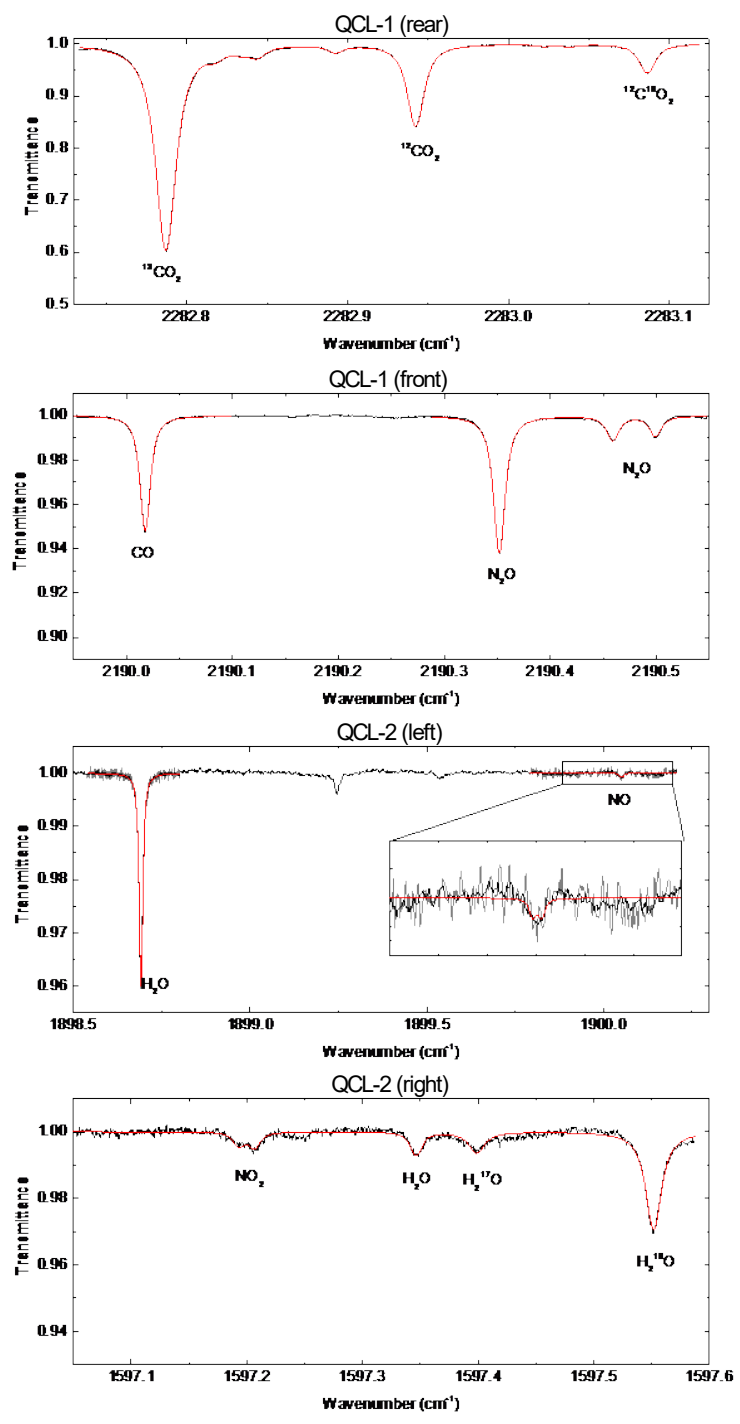

QCL-3

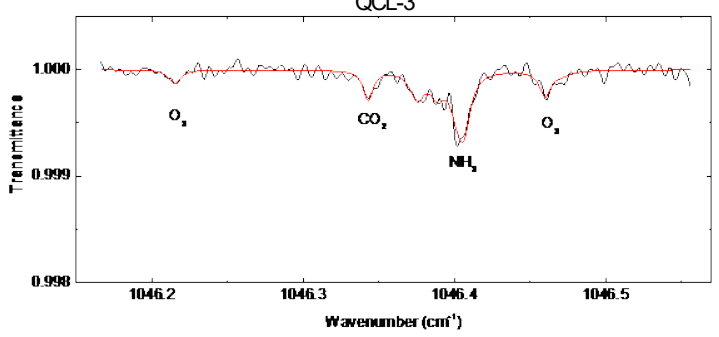

Figure 3: Normalized and fitted transmission spectra of the five wavelength regions covered by the QCLs. The Voigt-fit is shown in red, while the black line indicates the measured spectrum averaged over 1000 scans, i.e. for $1 \mathrm{~s}$. An exception is the NO spectrum, where the black line depicts an average of 20000 spectra and the gray line is an average of 1000 spectra. All spectra were recorded at a pressure of $75 \mathrm{hPa}, \mathrm{T}=25^{\circ} \mathrm{C}$ and $76 \mathrm{~m}$ optical path length. The mole fractions were as follows (given in brackets): $\mathrm{CO}_{2}(430 \mathrm{ppm}), \mathrm{CO}$ (200 ppb), N2O (327 ppb), $\mathrm{H}_{2} \mathrm{O}$ (0.7 \%), NO (14 ppb), NO 27 ppb), $\mathrm{NH}_{3}(5 \mathrm{ppb}), \mathrm{O}_{3}$ (15 ppb).

We assessed the instrument performance by measuring constant mole fractions of the target gases and applying an Allan-Werle variance analysis [26] to the retrieved values. For $\mathrm{NO}, \mathrm{NO}_{2}, \mathrm{O}_{3}$, and $\mathrm{NH}_{3}$ we used 
zero-air and for $\mathrm{CO}_{2}, \mathrm{~N}_{2} \mathrm{O}$, and $\mathrm{CO}$ a pressurized gas cylinder with mole fractions of $\mathrm{CO}_{2}(400 \mathrm{ppm}), \mathrm{N}_{2} \mathrm{O}$ (323 ppb) and CO (114 ppb). Figure 4 shows the Allan-Werle deviation plots for the gases mentioned above. Table 2 summarizes the results along with the corresponding absorption noise. The values reported here are up to 50 times higher than currently achievable noise levels in comparable single laser QCLAS instruments with reported absorption noise of $\sim 5 \times 10^{-6}$ at $1 \mathrm{~s}$ average and $\sim 5 \times 10^{-7}$ at the Allanminimum (about 100 seconds averaging) [5]. The significantly higher noise level for $\mathrm{CO}_{2}$ can be explained by a very strong absorption ( $>40 \%$ ), and changes in laboratory air $\mathrm{CO}_{2}$ mole fraction which impact the (unflushed) optical setup. Nevertheless, the $\mathrm{CO}_{2}$ detection limit is below the GAW extended compatibility goal of $\pm 0.2 \mathrm{ppm}$ [27]. The Allan-Werle analysis revealed no particular difference between the performance of dual-section device (QCL-1), the neighbor DFB (QCL-2), and the single DFB (QCL-3). The differences in achievable precision within our system and in comparison to state-of-the-art instrumentation can be mostly explained by other effects. We observed, for instance, that $\mathrm{N}_{2} \mathrm{O}$ averages much better (up to $1000 \mathrm{~s}$ ) than $\mathrm{CO}(100 \mathrm{~s})$ despite being measured with the same section of the dual-section $\mathrm{QCL}$. In that case the averaging of $\mathrm{CO}$ is likely to be influenced by concentration changes outside the multipass cell.
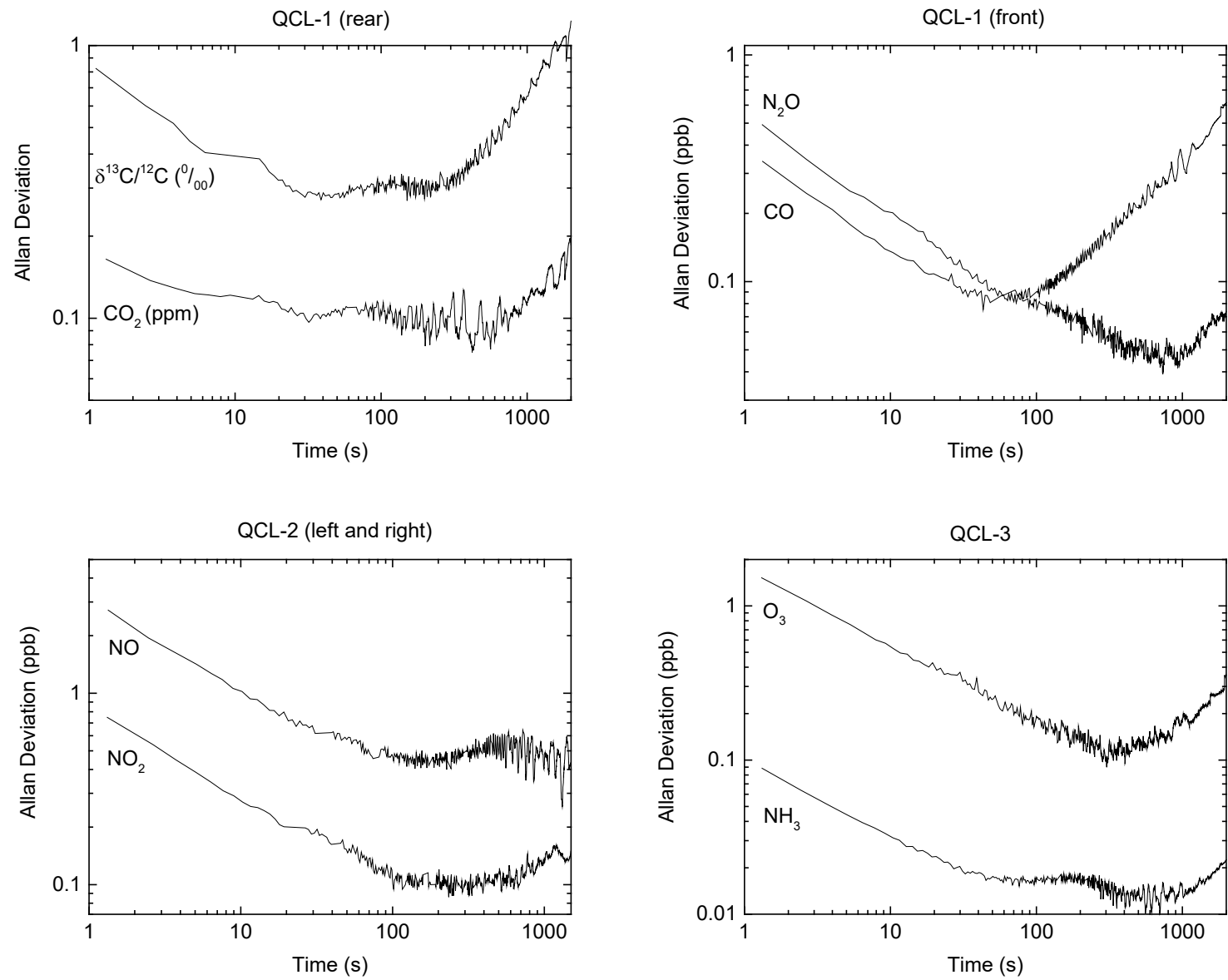

Figure 4: Allan-Werle deviation plots for the measured gas species. For $\mathrm{NO}, \mathrm{NO}_{2}, \mathrm{O}_{3}$, and $\mathrm{NH}_{3}$ zero air was measured, while in the case of $\mathrm{CO}_{2}, \mathrm{~N}_{2} \mathrm{O}$, and $\mathrm{CO}$ pressurized air was used.

The discrepancy between our setup and comparable single laser QCLAS instruments is mostly caused by a relatively high detector noise level, which has several reasons: (i) multiple lasers are combined with wavelengths from 4 to $10 \mu \mathrm{m}$ and, therefore, a broadband IR-detector with large active area $\left(1 \mathrm{~mm}^{2}\right)$ 
without immersion lens is needed, which has a $D^{*}$ (detectivity) up to two orders of magnitude lower than a detector optimized e.g. for 3 to $6 \mu \mathrm{m}$ wavelength. (ii) The lasers are still prototype devices that cannot compete with the performance of commercial devices neither in terms of optical power $(\sim 1 \mathrm{~mW})$ nor emission properties. (iii) There is a difference in integration time/duty-cycle leading to a lower number of spectra that can be averaged per time: whilst a single laser instrument can be operated at a duty cycle close to $100 \%$, the multi-species instrument is time multiplexed between five lasers resulting in a much lower duty-cycle (see above) per laser device. (iv) The data acquisition has a high bandwidth $(125 \mathrm{MHz})$ required for the faster tuning of the QCLs in iCW driving and is therefore more susceptible for high frequency noise.

In addition, to realize a compact optical layout, compromises were made on the optics and coupling of the laser beams to the multipass cell. We used fast optics for direct focusing of the QCL outputs to the multipass cell. This leads to chromatic aberration (in case of the dual-lasers), and therefore a compromise in focal position/beam waist size in the multipass cell. Furthermore, the fact that the neighbor DFB produces two separate beams that are $2.3 \mathrm{~mm}$ apart at the center of the cell leads to imperfect beam propagation and scattering on the coupling hole of the cell. These compromises can influence the achievable fringe-level, however, our results indicate that the measurement precision is mainly limited by detector noise. Consequently, those lasers with the lowest output power (Table 1) exhibit the highest absorption noise levels (see Table 2).

Table 2: Summary of Allan-Werle deviations representing the $1 \sigma$ limit of detection and the corresponding absorption noise given after one second integration time and at the Allan deviation minimum ("best"), which was typically reached between 100 and 300 seconds integration time. The numbers shown for $\delta^{13} \mathrm{CO}_{2}$ are in $\%$.

\begin{tabular}{|c|c|c|c|c|c|c|}
\hline \multirow[t]{2}{*}{ Species } & \multicolumn{2}{|c|}{ Precision [ppb] } & \multicolumn{2}{|c|}{ Absorption noise } & \multirow[t]{2}{*}{ DFB-QCL type } & \multirow[t]{2}{*}{ Device numbel } \\
\hline & $1 \mathrm{~s}$ & best & $1 \mathrm{~s}$ & best & & \\
\hline CO & 0.35 & 0.08 & $9.2 \mathrm{E}-05$ & $2.1 \mathrm{E}-05$ & Twin & $\mathrm{QCL}-1$ (front) \\
\hline $\mathrm{N}_{2} \mathrm{O}$ & 0.49 & 0.045 & $9.9 \mathrm{E}-05$ & $9.0 \mathrm{E}-06$ & Twin & QCL-1 (front) \\
\hline $\mathrm{CO}_{2}$ & 170 & 100 & $1.6 \mathrm{E}-04$ & $9.3 \mathrm{E}-04$ & Twin & QCL-1 (rear) \\
\hline$\delta^{13} \mathrm{CO}_{2}[\% \circ]$ & 0.9 & 0.28 & - & - & Twin & QCL-1 (rear) \\
\hline NO & 3 & 0.4 & 1.7E-04 & $2.2 \mathrm{E}-05$ & Neighbor & QCL-2 (left) \\
\hline $\mathrm{NO}_{2}$ & 0.8 & 0.1 & $1.6 \mathrm{E}-04$ & $2.0 \mathrm{E}-05$ & Neighbor & QCL-2 (right) \\
\hline $\mathbf{O}_{3}$ & 1.7 & 0.11 & $3.2 \mathrm{E}-05$ & 2.0E-06 & Single & $\mathrm{QCL}-3$ \\
\hline $\mathrm{NH}_{3}$ & 0.1 & 0.016 & $3.0 \mathrm{E}-05$ & $4.8 \mathrm{E}-06$ & Single & QCL-3 \\
\hline
\end{tabular}

Despite the fact that QCLAS is, in principle, an absolute analytical technique, calibrations were performed in order to improve the accuracy of the instrument. Table 3 shows a summary of the calibration factors that were applied. $\mathrm{CO}, \mathrm{N}_{2} \mathrm{O}, \mathrm{CO}_{2}$, and $\mathrm{NO}$ were calibrated to reference gases and show only small deviations of $<5 \%$ which is in the range of the uncertainty of the spectroscopic parameters of the HITRAN database [20]. Since $\mathrm{NO}_{2}$ calibration gases are difficult to obtain and tend to be unstable, $\mathrm{NO}_{2}$ was calibrated during ambient air measurements to a CLD (APNA 360, Horiba), which is the reference method for $\mathrm{NO}_{2}$ monitoring according to regulatory norm [1]. The calibration factor is likely to be overestimating the true $\mathrm{NO}_{2}$ mole fraction, because CLDs using catalytic converters have cross sensitivities to other nitrogen containing compounds $[3,4]$. Since $\mathrm{O}_{3}$ and $\mathrm{NH}_{3}$ are also unstable, calibration gases are not 
available or not reliable. Therefore, the $\mathrm{NH}_{3}$ measurement was not calibrated, but a conservative estimate of $\pm 20 \%$ was made based on the uncertainty of the line strengths of $10-20 \%$ stated in the HITRAN database [20].

In the case of $\mathrm{O}_{3}$ we calibrated our spectrometer using a UV-absorption instrument (Thermo 49i-PS), which serves as a transfer standard for regular quality control at the stations of the NABEL network. The instrument uses a dual-cell photometer to produce constant $\mathrm{O}_{3}$ mole fractions with a UV-lamp, and it is traceable to a standard reference photometer produced by NIST [25]. Its uncertainty results from the combination of the uncertainties of the reference standard and the UV photometer itself; it is less than $1 \%$ of the mole fraction reading for mole fractions $<250 \mathrm{ppb}$.

We measured $\mathrm{O}_{3}$ from the UV photometric standard with the QCLAS while stepwise increasing the concentration (Figure 5(a)). The obtained scatter-plot is shown in Figure 5(b), where the measured QCLAS mole fraction (4 min mean with $2 \sigma$ error bars) is plotted over the set mole fraction of the transfer standard ( $2 \sigma$ error bars). The measured zero-air values of the QCLAS showed an offset of about $7 \mathrm{ppb}$ (caused by interference fringes) and a total drift of $+2 \mathrm{ppb}$ during the course of the experiment ( $1 \mathrm{~h}$ ). We corrected for this drift by linear interpolation between the first and the last zero-air measurements and subtraction of the offset. The resulting scatter-plot shows an excellent linearity $\left(R^{2}=0.9995\right)$ for the instrument over the whole concentration span covering the range expected in environmental monitoring. However, the slope deviates by about $10 \%$ from unity. As mentioned above, this mismatch can partly be explained by the uncertainty of the HITRAN database, as it states uncertainties between 2 and $5 \%$ (where stated) for the line-intensities of $\mathrm{O}_{3}$ in the respective wavelength region [20]. Finally, some degree of $\mathrm{O}_{3}$ dissociation on the aluminum body of the multipass cell of the QCLAS can be expected as well.

(a)

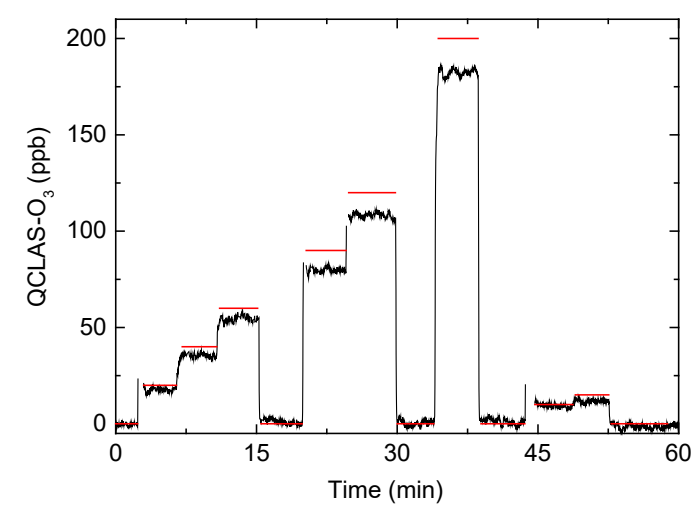

(b)

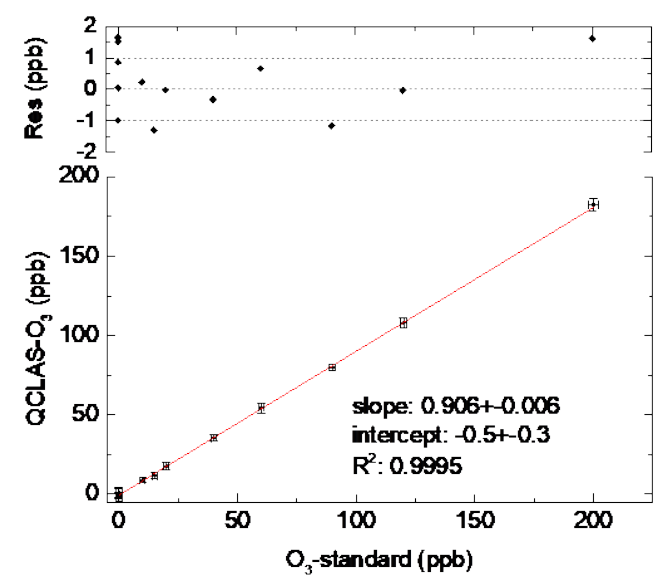

Figure 5: (a) Stepwise changes in $\mathrm{O}_{3}$ produced by NABEL transfer standard (Thermo 49i-PS) in red and measured by the QCLAS with 1 second time resolution (black line). A linear offset and drift-correction was already applied. (b) Scatter-plot of the averaged mole fraction steps measured by QCLAS vs. $\mathrm{O}_{3}$ reference values. 
Table 3: Summary of calibration factors for the QCLAS.

\begin{tabular}{|c|c|c|c|}
\hline Species & Calibration factor & Source for calibration & Device number \\
\hline CO & 1.01 & Ref. gas & QCL-1 (front) \\
\hline $\mathrm{N}_{2} \mathrm{O}$ & 1.05 & Ref. gas & $\mathrm{QCL}-1$ (front) \\
\hline $\mathrm{CO}_{2}$ & 1.02 & Ref. gas & QCL-1 (rear) \\
\hline NO & 0.99 & Ref. gas & QCL-2 (left) \\
\hline $\mathrm{NO}_{2}$ & 1.08 & Horiba, APNA 360 & QCL-2 (right) \\
\hline $\mathbf{O}_{3}$ & 1.1 & Thermo, 49i-PS & QCL-3 \\
\hline $\mathbf{N H}_{3}$ & $1.0 \pm 0.2^{*}$ & n.a. & QCL-3 \\
\hline
\end{tabular}

*estimated

\section{b. Measurement of ambient air at Empa/Dübendorf}

A short feasibility field-campaign of a few days was realized to demonstrate the instrument's capability for environmental monitoring. Figure 6 shows the recorded time-series of seven greenhouse gases and pollutants simultaneously measured in Dübendorf (Switzerland) in early December 2017. The previously determined calibration factors and the described drift correction were applied. The measurement period started on a Friday and ended on a Monday, therefore, emissions from the rush-hours can be observed. Despite the spatial separation of the gas inlets between our laboratory and the NABEL station, we see very good agreement for the $\mathrm{CO}$ and $\mathrm{CO}_{2}$ measurements. Differences are well within the range that would be expected due to the local variability and different exposure to emissions from road traffic. The discrepancy for $\mathrm{O}_{3}$ may appear slightly higher but, $\mathrm{O}_{3}$ is known to be very reactive, and as such, strong local gradients can be expected. Thus, the lower concentrations of the QCLAS are consistent with its smaller distance to the road traffic.

For the case, where the instruments share the same air inlet, i.e. for the $\mathrm{NO}$ and $\mathrm{NO}_{2}$, the QCLAS measurements agree well with the CLD in the laboratory. Although, $\mathrm{N}_{2} \mathrm{O}$ and $\mathrm{NH}_{3}$ were not compared to reference instruments, the retrieved mole fractions are within the expected values for a suburban site such as Dübendorf. The $\mathrm{N}_{2} \mathrm{O}$ is at the global background level of $329 \mathrm{ppb}$ with small variations of $\pm 1 \mathrm{ppb}$. The fast variations at the end of the time series are likely to be caused by emissions from road traffic. Finally, $\mathrm{NH}_{3}$ is at the expected level of 3 to $5 \mathrm{ppb}$. 


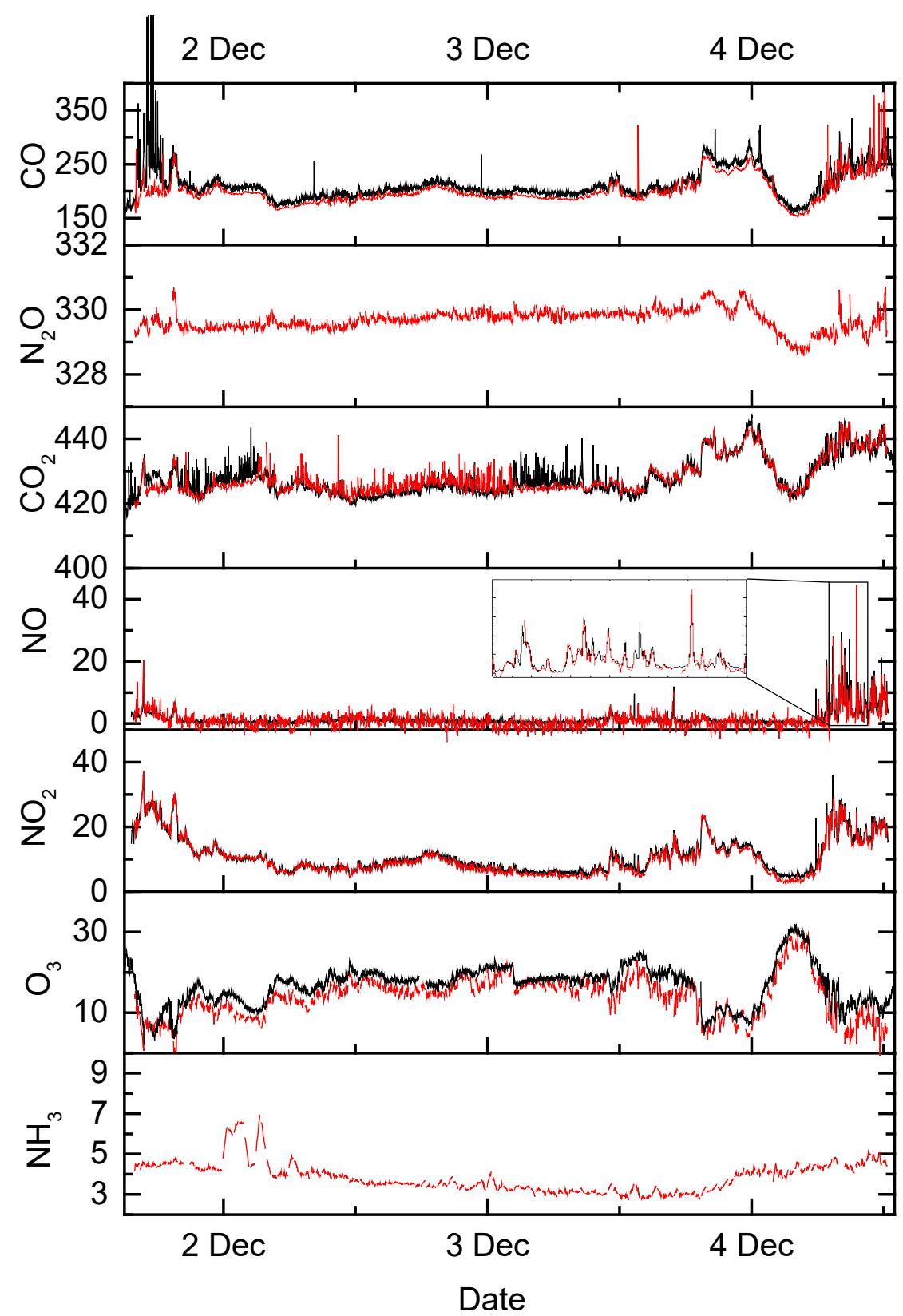

Figure 6: Time series of mole fractions measured by QCLAS (red traces) and reference instruments (black traces, where available). Mole fraction units are ppb (ppm for $\left.\mathrm{CO}_{2}\right)$. All data are 1 min averages. For the QCLAS data, correction factors/calibrations listed in Table 3 were considered and the hourly drift correction was applied.

\section{Conclusion}

The development and validation of a compact laser spectroscopic setup as an "all-in-one" solution for simultaneous measurement of the most important greenhouse gases and pollutants is described. The technique relies on state-of-the-art dual-wavelength DFB-QCL devices. Two different designs, dual-section and neighbor DFB-QCL devices, were employed to investigate their suitability for high-precision laser absorption spectroscopic applications. A dedicated hardware and software solution was employed, with compactness and low overall power consumption as key factors, supporting time-multiplexed intermittent-cw operation of multiple dual-DFB QCL devices, and to provide real-time spectral analysis of 
up to nine different target species. The hardware supports up to six lasers with a single multipass cell and a single detector.

The data quality was assessed by Allan-Werle variance analyses and by comparing to standard air quality monitoring equipment (where available). The achieved precisions and detection limits are sufficient for air quality monitoring and other atmospheric science applications.

Further extension of the target species can easily be realized, e.g. by replacing the single DFB-QCL at $9.6 \mu \mathrm{m}$ with a dual-wavelength DFB-QCL for covering the frequency around $1352 \mathrm{~cm}^{-1}$ to measure $\mathrm{CH}_{4}$ and $\mathrm{SO}_{2}$ [19]. This would complete the instrument to be a true all-in-one environmental monitoring station, opening a wide range of new possibilities in atmospheric sciences.

\section{Acknowledgements}

This work was financially supported by nano-tera.ch/IrSens II and the Swiss Federal Office for the Environment (FOEN) through "Umwelttechnologieförderung". We thank the NABEL team for providing the data from the monitoring station in Dübendorf and for supplying the reference gases. The continuous support of Beat Schwarzenbach (Empa) with $\mathrm{O}_{3}$ calibrations and NOx measurements was indispensable for this work. Christoph Zellweger (Empa) is acknowledged for providing the calibrated reference gas cylinder.

\section{References}

[1] EU, Directive 2008/50/EC of the European Parliament and of the Council of 21 May 2008 on ambient air quality and cleaner air for Europe, 2008.

[2] WMO/GAW, WMO Global Atmosphere Watch (GAW) Implementation Plan: 2016-2023, WMO, http://www.wmo.int/pages/prog/arep/gaw/gaw-reports.html, 2016.

[3] M. Steinbacher, C. Zellweger, B. Schwarzenbach, S. Bugmann, B. Buchmann, C. Ordóñez, A.S.H. Prevot, C. Hueglin, Nitrogen oxide measurements at rural sites in Switzerland: Bias of conventional measurement techniques, Journal of Geophysical Research: Atmospheres 112 (2007) D11307.

[4] E.J. Dunlea, S.C. Herndon, D.D. Nelson, R.M. Volkamer, F. San Martini, P.M. Sheehy, M.S. Zahniser, J.H. Shorter, J.C. Wormhoudt, B.K. Lamb, E.J. Allwine, J.S. Gaffney, N.A. Marley, M. Grutter, C. Marquez, S. Blanco, B. Cardenas, A. Retama, C.R. Ramos Villegas, C.E. Kolb, L.T. Molina, M.J. Molina, Evaluation of nitrogen dioxide chemiluminescence monitors in a polluted urban environment, Atmospheric Chemistry and Physics 7 (2007) 2691-2704.

[5] J.B. McManus, M.S. Zahniser, D.D. Nelson, J.H. Shorter, S.C. Herndon, D. Jervis, M. Agnese, R. McGovern, T.I. Yacovitch, J.R. Roscioli, Recent progress in laser-based trace gas instruments: performance and noise analysis, Applied Physics B-Lasers and Optics 119 (2015) 203-218.

[6] J.B. McManus, M.S. Zahniser, D.D. Nelson, Jr., J.H. Shorter, S. Herndon, E. Wood, R. Wehr, Application of quantum cascade lasers to high-precision atmospheric trace gas measurements, Optical Engineering 49 (2010).

[7] B. Tuzson, K. Zeyer, M. Steinbacher, J.B. McManus, D.D. Nelson, M.S. Zahniser, L. Emmenegger, Selective measurements of NO, NO2 and NOy in the free troposphere using quantum cascade laser spectroscopy, Atmospheric Measurement Techniques 6 (2013) 927-936.

[8] R.E. Baren, M.E. Parrish, K.H. Shafer, C.N. Harward, S. Quan, D.D. Nelson, J.B. McManus, M.S. Zahniser, Quad quantum cascade laser spectrometer with dual gas cells for the simultaneous analysis of mainstream and sidestream cigarette smoke, Spectrochimica Acta Part a-Molecular and Biomolecular Spectroscopy 60 (2004) 3437-3447. 
[9] M. Huebner, S. Welzel, D. Marinov, O. Guaitella, S. Glitsch, A. Rousseau, J. Roepcke, TRIPLE Q: A three channel quantum cascade laser absorption spectrometer for fast multiple species concentration measurements, Review of Scientific Instruments 82 (2011).

[10] C.L. Schiller, H. Bozem, C. Gurk, U. Parchatka, R. Königstedt, G.W. Harris, J. Lelieveld, H. Fischer, Applications of quantum cascade lasers for sensitive trace gas measurements of $\mathrm{CO}, \mathrm{CH} 4, \mathrm{~N} 2 \mathrm{O}$ and HCHO, Appl. Phys. B 92 (2008) 419-430.

[11] V. Catoire, C. Robert, M. Chartier, P. Jacquet, C. Guimbaud, G. Krysztofiak, The SPIRIT airborne instrument: a three-channel infrared absorption spectrometer with quantum cascade lasers for in situ atmospheric trace-gas measurements, Appl. Phys. B 123 (2017) 244.

[12] M. Razeghi, W.J. Zhou, S. Slivken, Q.Y. Lu, D.H. Wu, R. McClintock, Recent progress of quantum cascade laser research from 3 to $12 \mathrm{mu} \mathrm{m}$ at the Center for Quantum Devices Invited, Applied Optics 56 (2017) $\mathrm{H} 30-\mathrm{H} 44$.

[13] P. Rauter, F. Capasso, Multi-wavelength quantum cascade laser arrays, Laser \& Photonics Reviews 9 (2015) 452-477.

[14] M. Süess, R. Peretti, Y. Liang, J. Wolf, C. Bonzon, B. Hinkov, S. Nida, P. Jouy, W. Metaferia, S. Lourdudoss, M. Beck, J. Faist, Advanced Fabrication of Single-Mode and Multi-Wavelength MIR-QCLs, Photonics 3 (2016) 26.

[15] A. Straub, C. Gmachl, D.L. Sivco, A.M. Sergent, F. Capasso, A.Y. Cho, Simultaneously at two wavelengths (5.0 and $7.5 \mathrm{mu} \mathrm{m}$ ) singlemode and tunable quantum cascade distributed feedback lasers, Electronics Letters 38 (2002) 565-567.

[16] J. Jagerska, P. Jouy, A. Hugi, B. Tuzson, H. Looser, M. Mangold, M. Beck, L. Emmenegger, J. Faist, Dual-wavelength quantum cascade laser for trace gas spectroscopy, Applied Physics Letters 105 (2014).

[17] J. Jagerska, P. Jouy, B. Tuzson, H. Looser, M. Mangold, P. Soltic, A. Hugi, R. Broennimann, J. Faist, L. Emmenegger, Simultaneous measurement of $\mathrm{NO}$ and $\mathrm{NO} 2$ by dual-wavelength quantum cascade laser spectroscopy, Optics Express 23 (2015) 1512-1522.

[18] M. Süess, P.M. Hundt, B. Tuzson, S. Riedi, J. Wolf, R. Peretti, M. Beck, H. Looser, L. Emmenegger, J. Faist, Dual-Section DFB-QCLs for Multi-Species Trace Gas Analysis, Photonics 3 (2016) 24.

[19] F. Kapsalidis, M. Shahmohammadi, M. Süess, J.M. Wolf, E. Gini, M. Beck, M. Hundt, B. Tuzson, L. Emmenegger, J. Faist, Dual-wavelength DFB Quantum Cascade Lasers: sources for broadband trace-gas spectroscopy over the Mid-IR spectrum, Applied Physics B: Lasers and Optics (2018) submitted.

[20] L.S. Rothman, I.E. Gordon, Y. Babikov, A. Barbe, D.C. Benner, P.F. Bernath, M. Birk, L. Bizzocchi, V. Boudon, L.R. Brown, A. Campargue, K. Chance, E.A. Cohen, L.H. Coudert, V.M. Devi, B.J. Drouin, A. Fayt, J.M. Flaud, R.R. Gamache, J.J. Harrison, J.M. Hartmann, C. Hill, J.T. Hodges, D. Jacquemart, A. Jolly, J. Lamouroux, R.J. Le Roy, G. Li, D.A. Long, O.M. Lyulin, C.J. Mackie, S.T. Massie, S. Mikhailenko, H.S.P. Mueller, O.V. Naumenko, A.V. Nikitin, J. Orphal, V. Perevalov, A. Perrin, E.R. Polovtseva, C. Richard, M.A.H. Smith, E. Starikova, K. Sung, S. Tashkun, J. Tennyson, G.C. Toon, V.G. Tyuterev, G. Wagner, The HITRAN2012 molecular spectroscopic database, Journal of Quantitative Spectroscopy \& Radiative Transfer 130 (2013) 4-50.

[21] J.B. McManus, D.D. Nelson, S.C. Herndon, J.H. Shorter, M.S. Zahniser, S. Blaser, L. Hvozdara, A. Muller, M. Giovannini, J. Faist, Comparison of $\mathrm{cW}$ and pulsed operation with a TE-cooled quantum cascade infrared laser for detection of nitric oxide at $1900 \mathrm{~cm}-1$, Appl. Phys. B 85 (2006) 235-241.

[22] C. Liu, B. Tuzson, P. Scheidegger, H. Looser, B. Bereiter, M. Graf, M. Hundt, O. Aseev, D. Maas, L. Emmenegger, Laser Driving and Data Processing Concept for Mobile Trace Gas Sensing: Design and Implementation, Review of Scientific Instruments submitted (2018).

[23] L. Tombez, J. Di Francesco, S. Schilt, G. Di Domenico, J. Faist, P. Thomann, D. Hofstetter, Frequency noise of free-running 4.6um distributed feedback quantum cascade lasers near room temperature, Optics Letters 36 (2011) 3109-3111. 
[24] M. Fischer, B. Tuzson, A. Hugi, R. Broennimann, A. Kunz, S. Blaser, M. Rochat, O. Landry, A. Mueller, L. Emmenegger, Intermittent operation of QC-lasers for mid-IR spectroscopy with low heat dissipation: tuning characteristics and driving electronics, Optics Express 22 (2014) 7014-7027.

[25] NABEL, Technischer Bericht zum Nationalen Beobachtungsnetz für Luftfremdstoffe (NABEL), https://www.bafu.admin.ch/bafu/de/home/themen/luft/zustand/daten/nationales-beobachtungsnetzfuer-luftfremdstoffe--nabel-.html, 2017.

[26] P. Werle, R. Mucke, F. Slemr, The limits of signal averaging in atmospheric trace-gas monitoring by tuneable diode-laser absorption-spectroscopy (TDLAS), Applied Physics B-Photophysics and Laser Chemistry 57 (1993) 131-139.

[27] WMO/GAW, 18th WMO/IAEA Meeting on Carbon Dioxide, Other Greenhouse Gases and Related Tracers Measurement Techniques (GGMT-2015), WMO,

https://library.wmo.int/opac/doc num.php?explnum id=3074, 2015. 